\title{
A importância da legislação ambiental para a gestão ambiental pública municipal e no setor privado
}

\section{Diego Rafael dos Santos Peixotol}

diegorafaelsp@gmail.com

1. Universidade do Estado do Rio de Janeiro - UERJ, Maracanã, Rio de Janeiro, Brasil

Histórico Perspectiva Técnica:

Resumo: A estruturação da legislação ambiental brasileira é fruto de uma resposta a desastres ambientais e de uma pressão mundial para que os países atentassem para questões associadas ao meio ambiente. Essa legislação se apresenta como uma base para a implementação da gestão ambiental tanto no âmbito público municipal como no setor privado.

Palavras-chave: Direito ambiental, Gestão pública; Meio ambiente.

\section{The importance of environmental legislation for the municipal public environmental management and for the private sector}

Abstract: The Brazilian environmental legislation structuring is the result of a response to environmental disasters and global pressure for countries to address issues associated with the environment. This legislation presents itself as a basis for the environmental management implementation of both in the municipal public sphere and in the private sector.

Keywords: environmental law, public management; environment.

\section{La importancia de la legislación ambiental para la gestión ambiental pública municipal y para el sector privado}

Resumen: La estructuración de la legislación ambiental brasileña es fruto de una respuesta a desastres ambientales y de una presión mundial para que los países atenten para cuestiones relacionadas con el medio ambiente. Esta legislación se presenta como una base para la implementación de la gestión ambiental tanto en el ámbito público municipal y en el sector privado.

Palabras clave: Derecho ambiental, Gestión pública, Medio ambiente. 
A relação do Direito com o meio ambiente, no Brasil, começa no período colonial quando a Coroa Portuguesa editava leis específicas para controlar o corte excessivo de madeira nobre, como o Pau-brasil ou, até mesmo, limitar a poluição de corpos hídricos (MILARÉ, 2013).

Apesar disso, a legislação ambiental brasileira só começou a tomar corpo a partir da década de 60, quando o mundo já sentia as consequências dos problemas ambientais. Dentre os desastres mais marcantes destacam-se: o episódio de smog, ocorrido em Londres no ano de 1952, que levou a morte cerca de 4.000 pessoas e a contaminação por metais pesados da Baía de Minamata no Japão, devido ao lançamento de efluente industrial sem tratamento, o que resultou no nascimento de diversos bebês com problemas em 1956 (PHILIPPI JR et al, 2014).

Por isso, nesse século começou a preocupação do Estado brasileiro com as questões relativas ao meio ambiente, uma vez que na década de 70 foi iniciada uma forte discussão acerca da relação homem - natureza. Foi neste período que aconteceu a famosa Conferência de Estocolmo (Conferência das Nações Unidas sobre o Meio Ambiente Humano), em 1972, um dos grandes marcos para o cuidado com o ambiente, no qual diversos chefes de estado se reuniram para tratar sobre a degradação ambiental que vinha sendo realizada pela sociedade (DIAS, 2011).

Após esse primeiro debate global, o Brasil começou a criar órgãos administrativos específicos para tratar sobre meio ambiente. 0 primeiro foi a Secretaria Especial do Meio Ambiente - SEMA, em 1973, que estava voltada para a conservação do meio ambiente e o uso racional dos recursos ambientais. Na mesma década foram criados os primeiros órgãos ambientais estaduais, como a Fundação Estadual de Engenharia do Meio Ambiente - FEEMA, no Rio de Janeiro, e o Centro Tecnológico de Saneamento Básico, atualmente, Companhia Ambiental do Estado de São Paulo - CETESB, em São Paulo, ambos os órgãos tinham como função principal controlar a poluição ambiental proveniente de indústrias (WANDERFORDESMITH \& MOREIRA, 1985).

Aliado a isso, começaram a surgir legislações específicas a nível federal como a Lei $\mathrm{N}^{0}$ 6.803/80, que dispunha sobre as diretrizes para zoneamento industrial visando a localização correta de áreas críticas de poluição. Entretanto, somente em 1981 foi sancionada a mais importante lei brasileira que trata do meio ambiente, a Política Nacional de Meio Ambiente (Lei $\left.\mathrm{N}^{\circ} 6.938 / 81\right)$, trazendo em seu art $2^{\circ}$ o seu objetivo: 

privado

\begin{abstract}
“(...) a preservação, melhoria e recuperação da qualidade ambiental propícia à vida, visando assegurar, no País, condições ao desenvolvimento socioeconômico, aos interesses da segurança nacional e à proteção da dignidade da vida humana (...)" (BRASIL, 1981).
\end{abstract}

A Política Nacional de Meio Ambiente, além de apontar diretrizes e princípios, trouxe em seu bojo uma série de instrumentos para validar o objetivo da Lei, dentre eles destacam-se: a avaliação de impactos ambientais e o licenciamento e revisão de atividades efetiva ou potencialmente poluidoras. Esses dois instrumentos juntos representam grande parte da base para a atuação dos órgãos de controle ambiental, seja a nível federal, estadual ou municipal.

Já em 1988, a Constituição Federal inovou ao tratar especificamente sobre meio ambiente em seu art. 225 que segundo o caput:

\footnotetext{
"Todos têm direito ao meio ambiente ecologicamente equilibrado, bem de uso comum do povo e essencial à sadia qualidade de vida, impondo-se ao poder público o dever de defendê-lo e preservá-lo para as presentes e futuras gerações”.
}

Além disso, a Carta Magna faz menção a avaliação de impactos ambientais por meio do inciso IV, $\S 1^{0}$ incumbindo ao poder público exigir o estudo prévio de impacto ambiental para obras ou atividades que proporcionem significativa degradação ambiental (BRASIL, 1988).

Esse arcabouço legal, amadurecido ao longo dos anos, pavimentou o caminho para a atuação da gestão ambiental. Embora ela possua uma definição muito ampla, em suma, trata da administração de determinada atividade humana, seja ela empresarial ou não, visando otimizar o uso de recursos ambientais, minimizar os impactos negativos derivados da atividade e cumprir as legislações vigentes.

Dessa forma, a legislação ambiental está intimamente relacionada com realização da correta gestão ambiental, pois esta tem como premissa fundamental o atendimento à legislação ambiental.

Na esfera privada, a gestão ambiental se manifesta comumente por meio daqueles dois instrumentos da Lei $\mathrm{N}^{0}$ 6.938/81, a avaliação de impactos ambientais e o licenciamento ambiental. 0 licenciamento, especificamente, é exigido para qualquer empreendimento ou atividade que utiliza recursos naturais ou é efetivamente e/ou potencialmente poluidora. Logo, as empresas que se enquadram devem requerer junto ao órgão ambiental competente a sua licença ambiental para atestar que o empreendimento ou atividade está cumprindo os padrões ambientais. 
Dentro do processo de licenciamento, são identificados e avaliados os impactos ambientais inerentes à atividade, de forma a mitigar os impactos negativos e potencializar os impactos positivos.

Ainda na iniciativa privada, é crescente a preocupação com o meio ambiente, e isso se evidencia por exemplo, através dos sistemas de gestão ambiental adotados pelas empresas e muitas vezes certificados por organismos acreditadores, com base na ABNT NBR ISO 14.001/2015. Para algumas empresas isso representa, acima de tudo, um diferencial competitivo, uma vez que há segmentos em que é exigida a certificação por parte do fornecedor. Da mesma forma, bancos vêm condicionando a liberação de créditos para empresas quando estas possuem licença ambiental do empreendimento.

Já na esfera pública municipal, a legislação relacionada ao meio ambiente veio, principalmente, para subsidiar a gestão ambiental representada pelo papel de controle ambiental desempenhado pelos órgãos ambientais.

Em 2011, foi sancionada a Lei Complementar 140 que, segundo seu art. 1:

“(...) fixa normas, nos termos dos incisos III, VI e VII do caput e do parágrafo único do
art. 23 da Constituição Federal, para a cooperação entre a União, os Estados, o
Distrito Federal e os Municípios nas ações administrativas decorrentes do exercício
da competência comum relativas à proteção das paisagens naturais notáveis, à
proteção do meio ambiente, ao combate à poluição em qualquer de suas formas e à
preservação das florestas, da fauna e da flora” (BRASIL, 2011).

Essa Lei é conhecida por descentralizar o processo de licenciamento, concedendo aos municípios a competência de executar e fazer cumprir as Políticas Nacionais e Estaduais de Meio Ambiente, além de licenciar atividades e empreendimentos que tenham impacto ambiental local, desde que os órgãos municipais de meio ambiente possuam requisitos técnicos e estruturais mínimos. A descentralização é importante, pois desafoga os órgãos ambientais e, ao mesmo tempo, dá autonomia aos órgãos municipais uma vez que esses conhecem a realidade local.

Portanto, é notória a importância da legislação ambiental para que seja realizada uma gestão ambiental eficiente a nível privado e público municipal e consequentemente, prevenir e minimizar a ocorrência de danos ao meio ambiente, além de melhorar a qualidade de vida da sociedade. 

privado

\section{REFERÊNCIAS BIBLIOGRÁFICAS}

ABNT NBR IS0 14.001:2015, Sistema de gestão ambiental - Requisitos com orientações para uso. 3. ed. Associação Brasileira de Normas Técnicas (ABNT), 2015.

BRASIL. Lei Complementar $\mathbf{n}^{0}$ 140, de 8 de dezembro de 2011. Fixa normas, nos termos dos incisos III, VI e VII do caput e do parágrafo único do art. 23 da Constituição Federal, para a cooperação entre a União, os Estados, o Distrito Federal e os Municípios nas ações administrativas decorrentes do exercício da competência comum relativas à proteção das paisagens naturais notáveis, à proteção do meio ambiente, ao combate à poluição em qualquer de suas formas e à preservação das florestas, da fauna e da flora; e altera a Lei $\mathrm{n}^{\circ} 6.938$, de 31 de agosto de 1981. Disponível em: http://www.planalto.gov.br/ccivil_03/Leis/LCP/Lcp140.htm. Acesso em: 04 out. 2017.

BRASIL. Lei $\mathrm{n}^{\circ}$ 6.938, de 31 de agosto de 1981. Dispõe sobre a Política Nacional de Meio Ambiente, seus fins e mecanismos de formulação e aplicação, e dá providências. Disponível em: http://www.planalto.gov.br/ccivil_03/leis/L6938.htm. Acesso em: 03 out. 2017.

BRASIL. Constituição da República Federativa do Brasil, de 5 de outubro de 1988. Disponível em: http://www.planalto.gov.br/ccivil_03/constituicao/constituicaocompilado.htm. Acesso em: 04 out. 2017.

DIAS, R. Gestão ambiental: responsabilidade social e sustentabilidade. 2. ed. São Paulo: Atlas, 2011.

MILARÉ, Édis. Direito do Ambiente. 8. ed. São Paulo: Revista dos Tribunais, 2013.

PHILIPPI JR, Arlindo; ROMÉR0, Marcelo de Andrade; BRUNA, Gilda Collet. Curso de Gestão Ambiental. 2 ed. Barueri: Manole,2014.

WANDERFORDE-SMITH, G.; MOREIRA, I. V. D. Subnational government and EIA in the developing world: Bureaucratic strategy and political change in Rio de Janeiro, Brazil. Environmental Impact Assessment Review, v. 5, p. 223-238, 1985. 